\title{
Studies of Catecholamine Metabolism in Schizophrenia/Psychosis-I
}

\author{
James W. Maas, M.D., Salvador A. Contreras, M.D., Alexander L. Miller, M.D., \\ Nancy Berman, Ph.D., Charles L. Bowden, M.D., Martin A. Javors, Ph.D., \\ Ermias Seleshi, M.D., and Susan Weintraub, Ph.D.
}

\begin{abstract}
Acutely psychotic schizophrenic patients not taking antipsychotic medications and control subjects were studied before and during treatment with debrisoquin (DBQ), an inhibitor of monoamine oxidase, which does not penetrate into brain. Homovanillic acid (HVA) and 3-methoxy-4-hydroxyphenylglycol (MHPG) were measured in plasma, urine, and cerebrospinal fluid (CSF). Significant differences between patients and control subjects were more easily discerned during treatment with $D B Q$. In patients, HVA was increased in plasma but not in urine or CSF, although MHPG was
\end{abstract}

increased in all three fluids. There were many significant correlations between plasma MHPG and HVA levels and clinical ratings of psychoticism. Plasma MHPG correlated positively with both the severity of positive and negative symptoms and plasma HVA correlated only with positive symptom severity. These data suggest that both dopamine and norepinephrine (NE) metabolism are disturbed in acutely psychotic schizophrenic patients; disturbed NE metabolism may relate to negative symptoms as well. [Neuropsychopharmacology 8:97109, 1993]
REY WORDS: Schizophrenia; Psychosis; Dopamine; Norepinephrine; HVA; MHPG; Renal clearance; Neuroleptic actions

In 1963 Carlsson and Lindqvist reported that the administration of chlorpromazine or haloperidol to mice resultedin elevations of brain concentrations of 3-methoxytyramine, a metabolite of dopamine (DA). From these data they hypothesized that these drugs were exerting their antipsychotic effects via a blockade of DA receptors and that the increase in the metabolite occurred as the result of the activation of a feedback loop induced

From the Departments of Psychiatry (JWM, ALM, CLB, MAJ), and Pathology (SEW), The University of Texas Health Science Center at San Antonio; Department of Psychiatry (SAC), Texas Tech University Health Science Center, Lubbock, Texas; Ohio Permanente Medical Group(ES) Cleveland, Ohio; and the Department of Pediatrics (NB), Harbor-UCLA Medical Center, Torrance, California.

Address reprint requests to: James W. Maas, M.D., Department of Psychiatry, The University of Texas Health Science Center, 7703 Floyd Curl Drive, San Antonio, Texas 78284-7792.

Received January 23, 1992; revised June 18, 1992; accepted July 7 , 1992. by the receptor blockade (Carlsson and Lindqvist 1963). In the aggregate, these initial and subsequent basic neuropsychopharmacologic studies have led to the "DA hypothesis of schizophrenia or psychosis," which suggests that schizophrenia/psychosis is associated with either an increase in central nervous system (CNS) DA release or an increase in DA receptor sensitivity (for recent reviews see Davis et al. 1991; Seeman et al. 1987). Subsequent to the emergence of this "DA hypothesis," a large number of clinical studies dealing with the functioning of DA neurotransmitter systems in schizophrenia have been performed. The approaches to the clinical investigation of this hypothesis have included the use of catecholamine synthesis inhibitors, comparisons of neurotransmitters and their metabolites in the cerebrospinal fluid (CSF) and other body fluids of patients and control subjects, computerized tomography scans, assays of neurotransmitters and their metabolites in postmortem brain tissue, receptor studies, positronemission tomography (PET) scans, and studies of endocrine functions regulated by DA input. Each of these approaches to assessing the DA system function in 
brains of schizophrenics hasits problems and therefore, attention has also focused on the simpler approach of studying relationships between the DA metabolite, plasma homovanillic acid (HVA), and schizophrenic/ psychotic symptoms. Bowers et al. (1984), in a study of a diagnostically mixed group of psychotics, found that patients who had good outcomes with haloperidol treatment had significantly higher pretreatment plasma HVA concentrations than did those patients with poor outcomes. Further, the plasma HVA values in the good outcome group significantly decreased after 3 weeks of drug treatment whereas the poor outcome group's values were unchanged. This finding was replicated by Davila et al. in 1988. In studies of schizophrenic patients Pickar et al. $(1984,1986)$ found that neuroleptic treatment was associated with a time-dependent decrease in plasma HVA values over a 5 -week period and that this decrease was correlated with changes in psychosis ratings. Apparently all of the patients showed some degree of improvement, and it is thus difficult to know whether the plasma HVA decrease was associated with symptom change, per se, or represented a pharmacologic adaptation or "tolerance" to the neuroleptic. This issue is of interest because it has been reported that the development of tolerance, as assessed by changes in CSF HVA is associated with a favorable treatment outcome (Bowers et al. 1984). Davis et al. (1985), Muscettola et al. (1990) and Davidson et al. (199la,b) have found significant relationships between the severity of symptomatology in psychotic schizophrenics and concentrations of plasma HVA. Failure to find this association has also recently been reported (Javaid et al. 1990).

Although these studies of plasma HVA in schizophrenia and psychosis are most interesting and suggest empirical leads, a potential problem of interpretation arises. Homovanillic acid is formed both in the periphery and in the brain, with estimates indicating that of the total-body HVA formed, about $11 \%$ to $35 \%$, arises in brain (Bacopoulos et al. 1978, 1979; Elsworth et al. 1982; Maas et al. 1977, 1979b, 1988; Elchisak et al. 1979; Anggard et al. 1974; Kopin et al. 1988; Lambert et al. 1991). The problem of the peripheral production of HVA for the interpretation of results of studies with psychotic patients is particularly troublesome because plasma levels of DA can be increased by activity and changes in peripheral sympathetic nervous system activity as well as by stress and agonist challenges (Snider and Kuchel 1983; Van Loon et al. 1979a,b; Buhler et al. 1978). Measurements of concentrations of plasma metabolites may not give a measure of rates of synthesis or metabolism because the plasma concentration of any substance may change as a function of clearance rates (Potter et al. 1989), metabolic shunts, changes in extracellular fluid volume, rhythm of excretions, and the route of disposition of the metabolite. If one assumes that all of the metabolite is excreted in urine, as appears to be the case with HVA (Miller et al. 1987), assays of total metabolite present in urine may give a better measure of the rate of synthesis or metabolism of the substance under scrutiny than plasma concentrations.

Following an initial report by Karoum et al. (1974), our group and others have used debrisoquin (DBQ) as a research tool, for it appears to create a condition in which the peripheral measurement of HVA or 3-methoxy-4-hydroxyphenylglycol (MHPG) in plasma or urine better reflects respectively DA and perhaps norepinephrine (NE) system function within the CNS (Maas et al, 1979a, 1980, 1988; Swann et al. 1980; Kopin et al. 1983, 1988; Riddle et al. 1986 and unpublished observations). Debrisoquin is an antihypertensive drug having guanethidine-like properties, which inhibits monoamine oxidase (MAO) and does not enter brain (Medina et al. 1969; Kitchin and Turner 1966; Tomlinson and Mayor 1973). Given these properties, it was hypothesized that administration of DBQ would produce a decrease in production of HVA and MHPG in the periphery but not in the brain, thereby amplifying the relationships between central production of and peripheral measures of HVA and/or MHPG. Previous work with human subjects and subhuman primates has in part confirmed this hypothesis (Maas et al. 1988, 1979a; Swann et al. 1980; Riddle et al. 1986 and unpublished observations). Before administration of DBQ in subhuman primates there was no significant correlation between plasma HVA and the brain's production of this metabolite. During DBQ administration the brain's output of HVA was unchanged but plasma HVA concentrations were decreased and there was a modest positive correlation $(r=.55, p<.05, n=16)$ between plasma HVA levels and the brain's production of HVA (Maas et al. 1979b and unpublished observations).

A review of DA system function in schizophrenia/psychosis illustrates that the dose $K_{i}$ for neuroleptic drugs and the clinical dosage needed for therapeutic response are closely related and this is consistent with a role of DA in schizophrenia/psychosis. However, a variety of human clinical studies of the "DA hypothesis" have yielded more controversial or generally negative findings (Bunney 1978; Hornykiewicz 1978; Meltzer and Stahl 1976; Bowers 1980; van Kammen 1977; van Praag 1977; Haracz 1982; Gershon et al. 1967; Nasrallah et al. 1977; Persson and Roos 1969; Bowers et al. 1969; Rimon et al. 1971; Berger et al. 1980).

In contrast to DA, a role for altered NE system function in schizophrenia is more strongly supported by human studies than by animal investigations. For example, there are studies involving brain autopsy material to indicate that NE is increased in the nucleus accumbens (Farley et al. 1978), particularly in paranoid schizophrenics (Farley et al. 1980). Also, Ko et al. (1988) and Joseph et al. (1976) have reported statistically 
significant relationships between concentrations of plasma MHPG and severity of psychosis. Bowers et al. (1984) found that high plasma MHPG predicted good neuroleptic response. Van Kammen et al. (1990) noted CSF(NE) and MHPG correlated significantly with positive and negative symptoms. Four separate studies indicate that CSF NE is elevated in schizophrenic/ psychotic patients as compared with healthy control subjects (Gomes et al. 1980; Kemali et al. 1982; Sternberg et al. 1981; van Kammen et al. 1990). Breier et al. (1990) found that plasma NE levels correlated with both positive and negative symptoms of schizophrenia. Sternberg et al. (1982) and van Kammen and Antelman (1984) found that acute administration of the $\alpha_{2}$-adrenergic agonist clonidine did not produce the same quantitative decrease of plasmaMHPG that was seen in control and depressed subjects. They speculated that $\alpha_{2}$ presynaptic receptors modulating NE release may be less sensitive in schizophrenic patients. Data have been reported that support this hypothesis for a subgroup, but not all patients (Glazer et al. 1987). Van Kammen et al. (1989) reported that clonidine was possibly therapeubic for paranoid schizophrenics but not for other types of schizophrenics, whereas Freedman et al. (1982) found that clonidine was as effective as haloperidol for the treatment of schizophrenia/psychosis in patients who have previously responded well to neuroleptics.

In this paper we report significant differences between control and patient concentrations of MHPG and HVA in plasma, and of urinary output of MHPG (but not of urinary output of HVA). These differences were most consistently found during DBQ administration and they generally agree with other reports using the same paradigm but without the use of DBQ. We also note significant relationships between plasma MHPG concentrations and symptom severity (including negative symptoms), but not between negative symptoms and plasma HVA values, and develop the hypothesis that alterations in brain NE system function may be involved with both negative and positive symptoms and alterations in brain DA systems only with positive symptoms.

\section{MATERIALS AND METHODS}

\section{Subjects}

Patients included in this study were 25 men between the ages of 21 and 65 years who met research diagnostic criteria (RDC) (Spitzer et al. 1978) for schizophrenia. All patients were acutely ill and sufficiently symptomatic so that hospitalization was medically indicated. In several instances the recurrence of symptoms developed after patients had stopped taking neuroleptic medication. Patients receiving depot neuroleptics were not admitted to the study if the injection had been done within the preceding 2 months. Subjects were maintained without psychotropic drugs for 2 weeks after admission to the hospital. Occasional chloral hydrate was given for agitation. All patients were free of major medical illnesses and voluntarily agreed to participate after receiving a full explanation of the nature of the study. Two patients had no previous psychiatric hospital admissions but the others had had multiple admissions. Subjects were hospitalized on a psychiatric clinical research unit of the Audie L. Murphy Memorial Veterans' Hospital (ALMMVH), in San Antonio, Texas. Subjects were maintained on a low-tyramine, lowvanillymandelic acid diet and restricted from using alcohol and caffeine throughout the study. The study was approved by the Institutional Review Board.

Control subjects were a group of 10 males having the same age distribution as the patient group. These control subjects were free of diagnosable psychopathology using RDC as determined by two psychiatrists (J.W.M. and E.S.). Control subjects were also hospitalized at the ALMMVH on a clinical research unit and were subject to the same dietary restrictions as the patients. The timing and procedures for body fluid collections were similar to those for patients.

\section{Study Design}

On the 7th or 3rd day after admission to the hospital (patients and control subjects respectively) the subjects had blood samples drawn at 8:00 A.M. and 10:00 A.M. This is referred to as "off DBQ" baseline day 1 . For those patients who consented on this "off $D B Q$ " baseline day, a lumbar puncture was performed at 9:00 A.M., with the patient in the sitting position. A total of $14 \mathrm{ml}$ of CSF was removed from each patient, with the initial $2 \mathrm{ml}$ of CSF being used for clinical chemistry studies and the remaining $12 \mathrm{ml}$ for the determination of HVA and MHPG concentrations. Control subjects did not have this lumbar puncture performed on this "off $\mathrm{DBQ}^{\text {" base- }}$ line day. On the same day, 3.5-hour urine collections were obtained from patients and control subjects as follows. Subjects received nothing orally, except for water ad libitum, from midnight until the completion of the urine collection. Patients were kept at bedrest and were under a research nurse's observation the entire time. Urine was collected from 8:30 A.M. until noon. This methodology allowed us to control for diet and activity (Kendler et al. 1983), as well as assuring completeness of collection.

After these "off DBQ" samples had been obtained, subjects began receiving DBQ at a dosage of $10 \mathrm{mg}$ twice daily for the 1st day and $10 \mathrm{mg}$ four times daily thereafter. For the initial phases of this study patients received DBQ for 14 days before the second collection of biologic specimens, but subsequently this time was reduced to 7 days once it had been established that the 
decrements in plasma HVA associated with DBQ administration were equal at 7 and 14 days (Maas et al. 1985). Three subjects received $D B Q$ for 14 days and the rest for 7 days. No effect of the additional time on DBQ in metabolite levels assayed was seen when comparison was done with "runs" tests. Patients receiving DBQ for 7 or 14 days were pooled for this study. All control subjects received DBQ for 7 days. After $7(n=20)$ or 14 days $(n=3)$ of DBQ treatment, blood was again drawn at 8 A.M. and 10 A.M. and 3.5-hour urine specimens were obtained. This second blood drawing and urine collection are referred to as the "on DBQ" baseline. For consenting patients and control subjects, a lumbar puncture was performed on this "on DBQ" baseline day.

While taking $\mathrm{DBQ}$, patients and control subjects were given challenge tests with placebo, apomorphine, and haloperidol as follows. On the 1st day subjects were given either placebo or apomorphine on a randomized double-blind basis. On the 2 nd day they received whichever drug (apomorphine or placebo) they had not received on the 1st day. On the 3rd challenge day they were given haloperidol intramuscularly $(0.2 \mathrm{mg} / \mathrm{kg})$. It should be noted that the results of the placebo or apomorphine were the same (no effect) and the order of the type of drug was without effect (half-life of apomorphine is relatively short). The full results of these challenge tests will be reported elsewhere, but for this paper, the effects of the placebo challenge are presented to illustrate the time course of changes of HVA concentration in plasma.

Immediately after urine, plasma, and CSF collection, sodium metabisulfite $(50 \mathrm{mg} / \mathrm{ml})$ and deuterated standards were added to the specimens. Urine specimens were assayed for creatinine (Helger et al. 1974), and these values along with the nursing observations made during the collection period were used to determine completeness of collection.

\section{Analysis Procedures for HVA and DOPAC}

For the HVA and dihydroxyphenylacetic acid (DOPAC) analyses of urine, $0.5 \mathrm{ml}$ of urine was spiked with 0.5 $\mathrm{ml}$ of a combined 10-ng/ $\mathrm{\mu l}$ 4-hydroxy-3-methoxyphenylacetic-2, 2- $\mathrm{d} 2$ acid (d2-HVA) and 3,4-dihydroxyphenyld3-acetic-2, 2-d2 acid (d5-DOPAC) solution. Aliquots of $2.5 \mathrm{ml}$ of plasma and CSF were spiked with $250 \mu \mathrm{l}$ of a 1-ng/ $\mu \mathrm{l}$ d2-HVA, d5-DOPAC solution. After thorough mixing, specimens were acidified with $0.4 \mathrm{ml}$ of hydrochloric acid $(1.25 \mathrm{~N})$ per milliliter of sample. Urine specimens were further diluted with $1.2 \mathrm{ml}$ of distilled deionized water.

\section{Analysis Procedures for MHPG}

For MHPG analyses $2.5 \mathrm{ml}$ of CSF or plasma was added to vials containing $500 \mathrm{ng}$ of dry 3-methoxy-4-hydroxy- phenylglycol-d3 (d3-MHPG). Urine, $2.5 \mathrm{ml}$, was added to vials containing $5 \mu \mathrm{g}$ of dry d3-MHPG. All specimens were split into two equal aliquots and frozen at $-70^{\circ} \mathrm{C}$ until time of assay. Plasma, urine, and CSF samples were assayed for HVA, DOPAC, and MHPG using gas chromatography-mass spectroscopy (selected ion monitoring) methods as previously described (Maas et al. 1979a).

\section{Calculation of Clearance Rates}

Clearance rates were calculated by the formula $\mathrm{VC} / \mathrm{P}$ where $\mathrm{V}$ is volume of urine, $\mathrm{C}$ is the urine's concentration of the substance being studied and $\mathrm{P}$ is its plasma or serum concentration. The urine clearance values are expressed as milliliters per minute to allow comparison with values in the literature.

\section{Data Collection Analysis}

For independent samples $t$-tests were used to compare plasma and urinary metabolites between the patients and control subjects during the "off $\mathrm{DBQ}^{\text {" and "on }}$ $\mathrm{DBQ}^{\prime}$ " days. Repeated-measures analysis of variance (ANOVA) was used to determine whether there was a time effect on plasma HVA during the placebo challenge day and to determine if there were between group differences in the time effect.

\section{Platelet Assay}

Platelet MAO activity was determined by a modified version of the method described by Murphy et al. (1976) and used benzylamine as the substrate. For this assay, blood $(10 \mathrm{ml})$ was collected at $8 \mathrm{~A} . \mathrm{M}$. in specimen tubes containing acetic acid and kept on ice until centrifuged. Platelet-rich plasma was pooled two times and again centrifuged to obtain a platelet pellet. The pellet was resuspended in $2 \mathrm{ml}$ of Ringer's-citrate-dextrose buffer $(\mathrm{pH}, 6.5)$, split into aliquots, and frozen at $-70^{\circ} \mathrm{C}$ until the time of assay.

\section{Drugs}

Deuterated HVA, DOPAC, and MHPG were purchased commercially (Merck and Co, Inc., Isotopes, St. Louis, $\mathrm{MO})$. High-purity organic solvents were used for extraction procedures (Baxter, Burdick \& Jackson, Muskegon, MI). Derivatization chemicals included trifluoroacetic anhydride (Supelco Inc, Houston, TX), 3,3,3, 2,2-pentafluoropropanol (Regis Chemical, Morton Grove, IL), and pentafluoropropionic anhydride (Pierce Chemical, Rockford, IL).

\section{Psychometric Measurements}

During the first 7 days in the hospital, all patients underwent structured interviews during which the 
Table 1. A Comparison Between Patients and Control Subjects for HVA in CSF, Plasma, and Unine On and Off DBQ

\begin{tabular}{|c|c|c|c|c|c|c|c|c|}
\hline & \multicolumn{8}{|c|}{ HVA Off DBQ Baseline } \\
\hline & & Plasma & & & Urine & & CSF & \\
\hline \multirow[t]{3}{*}{ Controls } & $\begin{array}{r}8: 00 \text { А.M. } \\
13.4 \pm 4.6 \\
(n=25) \\
10.5 \pm 2.9 \\
(n=10)\end{array}$ & $p=\mathrm{NS}$ & $\begin{array}{r}10: 00 \text { А.M. } \\
11.6 \pm 3.9 \\
(n=25) \\
8.3 \pm 2.1 \\
(n=10)\end{array}$ & $p \leqslant 0.02$ & $\begin{array}{c}828.7 \pm 293.3 \\
(n=13) \\
674.5 \pm 192 \\
(n=10)\end{array}$ & $p=\mathrm{NS}$ & & \\
\hline & \multicolumn{8}{|c|}{ HVA On DBQ Baseline } \\
\hline & & Plasma & & & Urine & & CSF & \\
\hline Patients & $\begin{array}{l}8: 00 \text { А.м. } \\
6.6 \pm 3.1 \\
(n=25)\end{array}$ & $n<000 ?$ & $\begin{array}{r}10: 00 \text { А.M. } \\
5.9 \pm 2.4 \\
(n=25)\end{array}$ & & $\begin{array}{c}374.7 \pm 140.4 \\
(n=13)\end{array}$ & & $\begin{array}{c}49.2 \pm 30.6 \\
(n=13)\end{array}$ & \\
\hline Controls & $\begin{array}{r}4.1 \pm 1.4 \\
(n=10)\end{array}$ & $p \leqslant 0.002$ & $\begin{array}{l}3.5 \pm 0.9 \\
(n=9)\end{array}$ & $p \geqslant 0.0002$ & $\begin{array}{c}314.8 \pm 67.9 \\
(n=10)\end{array}$ & $p=\mathrm{NS}$ & $\begin{array}{c}28.3 \pm 17.9 \\
(n=10)\end{array}$ & $p=\mathrm{NS}$ \\
\hline
\end{tabular}

Values for CSF and plasma are expressed as nanograms per milliliter \pm SD and for urine as total $\mu \mathrm{g} / 3.5$ hours \pm SD. The number of subjects is given in parentheses and the significance of differences between patients and controls as $p$ values.

Schedule for Affective Disorders and Schizophrenia (SADS)-Lifetime Version was completed. After this the SADS-Change Version (SADS-C) and SADS-C Global Assessment Scale (GAS) (Spitzer and Endicott 1979) were obtained on the 7th day of hospitalization as well as after 7 or 14 days of $D B Q$ treatment. On these same days the Brief Psychiatric Rating Scale (BPRS) (Overall and Gorham 1962) was administered by one of us (S.A.C.). We also used items $(\# 3,7,13,16)$ from the BPRS to quantitate negative symptoms as detailed by Thiemann et al. (1987). Thought disorder subscales from the BPRS, SADS, and a psychosis subscale from the Nursing Evaluation Scale(NES) were chosen to quantify psychoticism. TheSADS-C GAS and BPRS were also used to measure overall illness severity. The thought disorder subfactor was obtained from the SADS-C scale using the sum of ratings on items 148 (severity of delusions), 149 (severity of hallucinations), 157 (impaired understanding), 160 (bizarre behavior), and 158 (inappropriate affect). From the NES, which is a modification of the Nurses' Observation Scale for Inpatient Eval-

Table 2. Clearance Rates Expressed as Milliliters per Minute Plus or Minus SD for HVA Under Two

Conditions for Patients and Controls

\begin{tabular}{lcc}
\hline & Off DBQ & On DBQ \\
\hline Patients & $332.4 \pm 131.7$ & $322.1 \pm 205.5$ \\
& $(n=13)$ & $(n=13)$ \\
Controls & $377.0 \pm 137.3$ & $425.7 \pm 136$ \\
& $(n=9)$ & $(n=9)$ \\
\hline
\end{tabular}

Cearances were calculated as urine concentration $\times$ urine volume divided by plasma concentration. There were no effects of diagnosis or DBQ found by repeated-measures ANOVA. uation (Honigfeld and Klett 1965), a psychosis subscale was derived. (Items were 1 [crazy, bizarre manner], 2 [makes unrealistic plans], 3 [is suspicious], 4 [is delusional], and 11 [is hallucinating]). Correlations between plasma measures of metabolite and behavior were made by taking the mean morning values of metabolite measures before and after 7 days of DBQ treatment and looking at their relationship to the behavioral rating on the same day.

\section{RESULTS}

We compared hospitalized patients and healthy control subjects, using data from the "on" and "off" DBQ days.

The results for urine, plasma, and CSF analyses of HVA for patients and control subjects are shown in Table 1. During the "off DBQ" condition plasma HVA concentrations in schizophrenics exceeded those of control subjects on one but not the other time of blood sampling. Urine values of HVA for the patients and controls did not differ at this time. During DBQ administration these differences in plasma HVA between patients and control subjects were more clearly evident, but, as before, urine HVA values for the two groups did not differ between patients and controls.

This disparity between urinary and plasma HVA levels could have occurred because plasma levels of HVA changed as a function of a variety of factors including renal clearance (Potter et al. 1989). However, as shown in Table 2 there were no significant differences in HVA clearance between groups nor was there a significant effect on renal clearance of DBQ. The calcu- 
Table 3. A Comparison Between Patients and Control Subjects for DOPAC in CSF, Plasma, and Urine On and Off DBQ

\begin{tabular}{|c|c|c|c|c|c|c|c|c|}
\hline & \multicolumn{8}{|c|}{ DOPAC Off DBQ Baseline } \\
\hline & \multicolumn{3}{|c|}{ Plasma } & & \multicolumn{2}{|l|}{ Urine } & \multicolumn{2}{|l|}{ CSF } \\
\hline \multirow[t]{3}{*}{ Controls } & $\begin{array}{r}8: 00 \text { A.M. } \\
2.4 \pm 1.5 \\
(n=24) \\
3.0 \pm 0.9 \\
(n=10)\end{array}$ & $p=\mathrm{NS}$ & $\begin{array}{r}10: 00 \text { A.M. } \\
2.4 \pm 1.6 \\
(n=25) \\
\\
2.8 \pm 1.3 \\
(n=10)\end{array}$ & $p=\mathrm{NS}$ & $\begin{array}{c}194.5 \pm 140.4 \\
(n=13) \\
162.6 \pm 57.7 \\
(n=10)\end{array}$ & $p=\mathrm{NS}$ & & \\
\hline & \multicolumn{8}{|c|}{ DOPAC On DBQ Baseline } \\
\hline & & Plasma & & & Urine & & CSF & \\
\hline Patients & $\begin{array}{r}8: 00 \text { A.M. } \\
0.9 \pm 0.5 \\
(n=24)\end{array}$ & \multirow[b]{2}{*}{$p=\mathrm{NS}$} & $\begin{array}{c}10: 00 \text { A.M. } \\
1.1 \pm 0.8 \\
(n=24)\end{array}$ & \multirow[b]{2}{*}{$p=\mathrm{NS}$} & $\begin{array}{c}74.3 \pm 28.7 \\
(n=12)\end{array}$ & \multirow[b]{2}{*}{$p=\mathrm{NS}$} & $\begin{array}{r}3.8 \pm 7.5 \\
(n=13)\end{array}$ & \multirow[b]{2}{*}{$p=\mathrm{NS}$} \\
\hline Controls & $\begin{array}{r}1.3 \pm 1.7 \\
(n=10)\end{array}$ & & $\begin{aligned} 0.7 & \pm 0.4 \\
(n & =8)\end{aligned}$ & & $\begin{aligned} 66.7 & \pm 17.2 \\
(n & =10)\end{aligned}$ & & $\begin{array}{r}8.6 \pm 6.6 \\
(n=10)\end{array}$ & \\
\hline
\end{tabular}

Values for CSF and plasma are expressed as nanograms per milliliter \pm SD and forurine as total $\mu g / 3.5$ hours \pm SD. The number of subjects is given in parentheses and the significance of differences between patients and controls as $p$ values.

lations for clearance of HVA by patients and control subjects were done on a subset of patients (those with both plasma and urinary values for HVA). The disparity between plasma and urinary HVA comparisons was also noted in the subset.

Plasma concentrations of metabolites may also differ secondary to metabolic shunts (or a lack thereof). We therefore assayed another metabolite of DA, DOPAC, in plasma and urine. As may be seen in Table 3 there were no significant differences in DOPAC between patients and controls in plasma, urine, or CSF. The differences between patients and control subjects in plasma HVA, but not urinary HVA, may have occurred because the system was not at a steady state and/or the diurnal rhythms for patients and control subjects were markedly different. We therefore looked at changes in plasma HVA over a 3-hour period in both patients and controls while both groups were receiving DBQ. The results are shown in Figure 1. An ANOVA with repeated measures indicated a strong time effect for both patients $(p<.0001)$ and control subjects $(p<.0001)$, and that overall patients had signifcantly greater plasma HVA concentrations than control subjects $(p=.0007)$, but there were no differences in the patterns of the plasma HVA rhythm seen in patients versus controls. There were no diagnosis $\times$ time interactions. Thus, the difference found for $\mathrm{pl} \boldsymbol{r}^{-} \mathrm{ma}$ HVA between patients and controls but not for urinary HVA is not thought to be a function of the difference in time course of plasma HVA levels between the two groups.

The results for plasma, urine, and CSF MHPG are shown in Table 4. During the "off DBQ" period the urinary values of MHPG were significantly higher in pa- tients than in controls, but plasma levels were not. After DBQ administration both plasma and urinary values for MHPG were higher in patients as compared to control subjects.

In contrast to HVA, MHPG can be further metabolized to vanillylmandelic acid (VMA) and/or its conjugates. We also measured free MHPG in plasma, as well as total (free and conjugated) MHPG in urine,

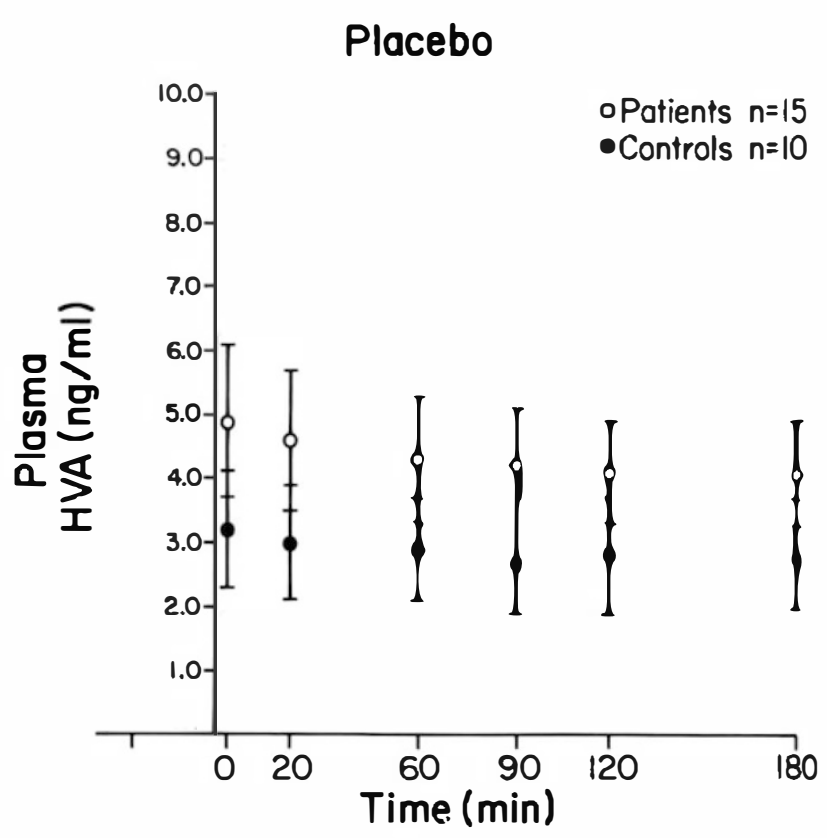

Figure 1. Plasma HVA (ng/rnl) in patients and control subjects following subcutaneous injection of placebo. All patients and control subjects were on DBQ for at least 7 days and off neuroleptics for at least 14 days. 
Table 4. A Comparison Between Patients and Control Subjects for MHPG in CSF, Plasma, and Urine On and Off DBQ

\begin{tabular}{|c|c|c|c|c|c|c|c|c|}
\hline & \multicolumn{8}{|c|}{ MHPG Off DBQ Baseline } \\
\hline & & Plasma & & & Urine & & CSF & \\
\hline Patients & $\begin{array}{c}8: 00 \text { А.M. } \\
4.0 \pm 1.5 \\
(n=25)\end{array}$ & \multirow{3}{*}{$p=\mathrm{NS}$} & $\begin{array}{c}10: 00 \text { A.M. } \\
4.2 \pm 1.7 \\
(n=23)\end{array}$ & \multirow[b]{2}{*}{$p=\mathrm{NS}$} & $\begin{array}{c}586.8 \pm 156.1 \\
(n=8)\end{array}$ & \multirow{3}{*}{$p \leqslant 0.0001$} & & \\
\hline Controls & $\begin{array}{r}3.2 \pm 1.2 \\
(n=10)\end{array}$ & & $\begin{array}{r}3.3 \pm 1.0 \\
(n=10)\end{array}$ & & $\begin{array}{c}227.8 \pm 98.4 \\
(n=10)\end{array}$ & & & \\
\hline \multicolumn{7}{|c|}{ MHPG On DBQ Baseline } & & \\
\hline & & Plasma & & & Urine & & CSF & \\
\hline Patients & $\begin{array}{c}8: 00 \text { A.M. } \\
1.3 \pm 0.5 \\
(n=23)\end{array}$ & \multirow[b]{2}{*}{$p \leqslant .001$} & $\begin{array}{c}10: 00 \text { A.M. } \\
1.3 \pm 0.6 \\
(n=23)\end{array}$ & \multirow[b]{2}{*}{$p \leqslant .002$} & $\begin{array}{c}196.0 \pm 84.6 \\
(n=8)\end{array}$ & \multirow[b]{2}{*}{$p \leqslant 0.002$} & $\begin{aligned} 4.3 & \pm 1.4 \\
(n & =13)\end{aligned}$ & \multirow[b]{2}{*}{$p \leqslant 0.01$} \\
\hline Controls & $\begin{array}{c}0.8 \pm 0.2 \\
(n=9)\end{array}$ & & $\begin{array}{c}0.9 \pm 0.2 \\
(n=8)\end{array}$ & & $\begin{aligned} 59.4 & \pm 25.9 \\
(n & =10)\end{aligned}$ & & $\begin{array}{r}2.9 \pm 0.8 \\
(n=10)\end{array}$ & \\
\hline
\end{tabular}

Values for CSF and plasma are expressed as nanograms per milliliter \pm SD and for urine as total $\mu \mathrm{g} / 3.5$ hours \pm SD. The number of subjects is given in parentheses and the significance of differences beween patients and controls as $p$ values.

where it is approximately $95 \%$ conjugated. Therefore clearance rates could not be calculated for MHPG.

Because of the possible relationships between the functioning of DA and NE systems (Antelman and Caggiula 1977; Grenhoff and Svensson, 1989), we constructed ratios of MHPG to HVA for all patients and control subjects and then compared this ratio between the schizophrenic and control subjects. We also correlated these ratio values with the behavioral variables. No significant differences or relationships were found except for the expected difference between patients and control subjects for the urinary MHPG/HVA ratio.

That the finding of an increase in urinary and plasma MHPG or the increase in plasma HVA in patients is not an artifact of greater MAO inhibition in control subjects is suggested by the data (Table 5), which indicate that the degree of MAO inhibition in platelets

Table 5. Platelet MAO Values for Patients and Control Subjects

\begin{tabular}{lcc}
\hline & $\begin{array}{c}\text { Off DBQ } \\
\text { (Day 1) }\end{array}$ & $\begin{array}{c}\text { On DBQ } \\
\text { (Day 8) }\end{array}$ \\
\hline Patients & $45.6 \pm 17.1$ & $20.8 \pm 13.6$ \\
& $(n=17)$ & $(n=18)$ \\
Controls & $38.9 \pm 20.3$ & $14.5 \pm 5.8$ \\
& $(n=10)$ & $(n=10)$ \\
\hline
\end{tabular}

Values are means \pm SD. The number of patients or controls is given in parentheses. Differences between patients and controls on or off DBQ are not significant, nor is the decrement in MAO associated with $\mathrm{DBQ}$ administration significantly different between patients and controls. However the absolute change in MAO activity associated with DBQ administration is highly significant $(p<0.006)$ for both patients and controls, respectively. is not significantly different for patients and controls receiving $\mathrm{DBQ}$. Patient and control groups were matched for gender and had similar age distributions. Height was not significantly different between the patients and controls. Although the patients were significantly heavier, no significant relationships between body weight and any of the metabolite values in any of the body fluids examined were found. Creatinine values for the 3.5-hour urine samples were not significantly different across days, suggesting that the collections were complete (data not shown).

We examined interrelationships between behavioral measures and plasma concentrations of HVA and MHPG before and during DBQ administration. Results with HVA have been previously reported (Maas et al. 1988). In brief, plasma HVA was significantly correlated $(p<.01)$ with the SADS-C GAS, the SADS-C Thought Disorder Factor, the total BPRS score, and the psychosis subscale of the NES during, but not before, DBQ administration. In the present study (Table 6) we found that plasma MHPG was positively correlated with positive symptoms of schizophrenia, but not with anxiety or aggression. Plasma MHPG was also positively correlated with the negative symptom score as measured with the BPRS $(r=0.68, n=15, p<.01)$. These relationships were generally stronger for patients on $\mathrm{DBQ}$ than off DBQ. In contrast to plasma MHPG, the correlation between negative symptoms and plasma HVA on DBQ was not significant $(r=.204, n=15, p=.448$ ). Because of a very weak trend toward a correlation between the BPRS disturbed thought and negative symptoms subscales $(r=.344, n=15)$, a partial correlation coefficient between negative symptoms (BPRS) and plasma MHPG was computed taking into account this 
Table 6. Correlations of MHPG with Clinical Ratings

\begin{tabular}{lll}
\hline Correlation & Off DBQ & On DBQ \\
\hline Plasma MHPG & $r=-0.420$ & $r=-0.701$ \\
vs. SADS-C GAS & $\begin{array}{l}r=0.058 \\
n=21\end{array}$ & $\begin{array}{l}p=0.001 \\
n=18\end{array}$ \\
Plasma MHPG vs. SADS-C & $r=0.463$ & $r=0.646$ \\
Thought Disorder factor & $p=0.030$ & $p=0.003$ \\
& $n=22$ & $n=19$ \\
Plasma MHPG vs. & $r=0.337$ & $r=0.766$ \\
total BPRS & $p=0.125$ & $p=0.0001$ \\
& $n=22$ & $n=20$ \\
Plasma MHPG & $r=0.215$ & $r=0.570$ \\
vs. BPRS DT & $p=0.337$ & $p=0.011$ \\
& $n=22$ & $n=19$ \\
Plasma MHPG vs. BPRS & $r=-0.017$ & $r=-0.284$ \\
agitation/excitement & $p=0.942$ & $p=0.238$ \\
& $n=22$ & $n=19$ \\
Plasma MHPG vs. psychosis & $r=0.662$ & $r=0.777$ \\
subscale of the NES & $p=0.007$ & $p=0.002$ \\
& $n=15$ & $n=13$ \\
Plasma MHPG vs. negative & $r=-$ & $r=0.66^{*}$ \\
symptoms & $p=-$ & $p=0.01$ \\
& $n=-$ & $n=15$ \\
\hline
\end{tabular}

Values are Pearson correlation coefficients for plasma MHPG and behavioral measures off and on BDQ. Schedule for Affective Disorders and Schizophrenia-Change Version (SADS-C) GAS refers to the SADS-C global assessment scale; BPRS total refers to the total Brief Psychiatric Rating Scale score; BPRS DT refers to the distured thinking factor of the Brief Psychiatric Rating scale; NES refers to the Nursing Evaluation Score. ( ${ }^{\star} \mathrm{A}$ partial correlation coefficient. See text.)

latter relationship. This corrected correlation coefficient was $r=.66, n=15, p<.01$.

\section{DISCUSSION}

The major findings of this work may be summarized as follows. In the comparison between acutely psychotic schizophrenic patients and control subjects, plasma MHPG and HVA levels were increased, CSF levels of MHPG but not of HVA were increased, and urinary output of MHPG but not of HVA was increased. Correlations of clinical measures of thought disorder and psychotic behavior with plasma levels of MHPG and HVA were robust. All of these findings were stronger when patients and control subjects were treated with $D B Q$. We hypothesize that this may be because with DBQ it is possible to obtain a clearer picture of CNS events. However, it is also true that DBQ may produce a reduction in the group variance of metabolite values by other unspecified mechanisms and this may make statistical comparisons sharper. This is not to say that differences between patients and controls cannot be found without $\mathrm{DBQ}$, because many other groups have reported such differences. The fact that differences in HVA and MHPG emerge more clearly with DBQ treatment does suggest that differences in concentrations of neurotrans. mitter metabolites found without DBQ are more likely attributable to changes in CNS rather than peripheral neurotransmission. This discussion will focus on: 1 ) the evidence for disturbed NE metabolism in schizophrenia; 2) the possible interpretations of the apparent discrepancy between altered plasma HVA without changes in urine and CSF HVA; and 3) exploration of NE-DA interactions as they may relate to the findings in this study.

Our findings of positive and significant relationships between plasma MHPG and both positive and negative symptoms are in general agreement with noradrenergic changes that have been hypothesized ot reported by others (Bowers et al. 1984; Ko et al. 1988; van Kammen et al. 1990; Stein and Wise 1971). The fact that our most robust findings were found when subjects were receiving DBQ does strengthen the likelihood that the findings can be related specifically to events in brain. The finding of an increase in MHPG in the patient group in urine and plasma is consistent with the hypothesis (Sternberg et al. 1982) that there are subsensitive $\alpha_{2}$ presynaptic adrenergic receptors in schizophrenia and that patients with this illness have an increased release and metabolism of NE.

Our findings of no difference in urinary HVA, with or without $\mathrm{DBQ}$, in patientsversus control subjects does suggest that the increased plasma HVA concentrations in plasma of schizophrenics reported here and in numerous other studies may not mean that there is increased synthesis of DA by whole-brain in schizophrenic patients. Comments about this disparity are as follows.

The gas chromatography-mass spectrometry method has a coefficient of variation of $5 \%$ and in other work has been accurate enough to detect differences in plasma HVA of $0.2 \mathrm{ng}$ (approximately 5000 times this concentration is found in urine). Thus, problems with analytic methods are probably not an explanation. In nonhuman primates, almost all (about 95\%) HVA isexcreted into urine and HVA gives a good overall measure of DA synthesis (Miller et al. 1987). It seems likely that in humans, routes of HVA excretion other than urine are not important. If the half-life of HVA were very long, it might mean that urinary values of HVA would more closely reflect past rather than present concentrations of plasma HVA. This does not appear to be the case, however, as the half life of HVA is reported to be about 1 hour (Elchisak et al. 1979; Anggard et al. 1974). Alternatively, the patients may not have been at a steady state or were different from the control subjects in terms of diurnal variation of HVA. However, our finding of a strong time effect during the placebo challenge for both patients and controls argues against this possibility. We also found no differences between 
patients and control subjects in renal clearance of plasma HVA. The sample size from which the clearance data were calculated is relatively small and this part of our work should be repeated. Unfortunately, values for both urine and plasma were collected on a smaller number of individuals than the total studied. Finally, these findings with urinary and plasma HVA might be secondary to differences between patients and control subjects with the patients having a metabolic shunt to DOPAC in the kidney. The DOPAC data as given in Table 3, however, do not support this possibility.

The finding of no apparent difference in the synthesis of DA between patients and controls, as reflected in urinary HVA, is consistent with the many studies that have reported no differences in CSF HVA between patients and control subjects (Berger et al. 1980; Bowers 1973; Bowers et al. 1969; Winblad et al. 1979; Nyback et al. 1983; Persson and Roos 1969; Rimon et al. 1971). This is not to say that differences between patients and control subjects in DA system function are not present, but rather to suggest that the difference is not in total over all synthesis. There could be differences in the patterns of impulse flow in DA systems. For example, bursts of DA neuronal firing occurring as 100 pulses in a short period might not be different in terms of HVA production from a steady monotonic fring of 100 pulses occurring over a longer period, but the functional significance could be quite large. Alternatively, different DA systems could have opposite changes in activity, leading to no detectable overall change in HVA output (Davis et al. 1991). Moreover, small changes in one system might be diluted out when overall brain synthesis is measured. A recent study does indicate that most HV Afrom human brain is from subcortical structures (Lambert et al. 1991).

One important caveat should be noted. When the study began we attempted to study 24-hour urine specimens from patients. Because of difficulties around diet, activity, and completeness of collection these collections proved not to be reliable or useful. Later in the study we switched to the 3.5-hour collections, with satisfactory results. This meant, however, that we were able to obtain results on urine only in a subset of patients $(n=10)$. Given the standard deviation of urinary HVA determinations and setting $\alpha$ at 0.05 , a power analysis indicates that with this number of patients the efficiency is only about $65 \%$. Thus, it seems possible that if a larger number of patients had been studied, a significant difference in urinary HVA between patients and control subjects might have been found.

Initially, our patients were not taking any medication for 1 week and then were receiving DBQ for another 7 to 14 days and were off psychotropic medication during this time. Thus they received a minimal neuroleptic washout of 2 weeks. Observations by other groups of investigators suggest that this 2 week washout period may be satisfactory. For example, Bunney and Grace (1978) found that DA cells in the rat diencephalon were in depolarization block after chronic administration of neuroleptics but began to fire normally after 2 weeks without medication. Studies with PET scans that were recently reported indicate that the brain is cleared of all neuroleptics within 10 to 12 days after patients cease taking medication (Farde et al. 1988). However, Pickar et al. $(1984,1986)$ reported that plasma HVA values increased at the 5th week of washout. If this pattern had been obtained in our study it would mean that our schizophrenic patients would have had even higher values than those reported here and our findings of significant differences for HVA and MHPG might have been amplified if we had used a longer washout time. Most of our patients were very sick, agitated, and aroused at the time biologic samples were obtained. Other authors (Bowers 1978; Ashcroft et al. 1966) have commented upon the elevated CSF HVA values that are seen with psychotic patients. For example, Bowers (1978) noted that the more acute the onset, the more disturbed the patient, and the greater the psychosis, the higher the level of CSF HVA. In an initial report on this problem, Ashcroft et al. (1966) also noted that patients who were more excited were those who had the higher CSF HVA levels. The results of our behavioral-chemical analyses support the possibility that we had higher plasma metabolite values because our patients were quite ill and psychotic. The lack of any significant correlation of the anxiety-agitation factor on the BPRS with any biochemical measure does not support the suggestion (Ashcroft et al. 1966) that these relationships were due solely to increased anxietyagitation. However, activity in patients is difficult to quantitate and it cannot be ruled out that an activity variable may have accounted at least in part for our findings.

Earlier published work indicated that for the NE metabolite MHPG about one-half of the MHPG in urine was derived from the $\mathrm{CNS}$. However, subsequent work indicates that MHPG is partially converted to VMA and, in contrast to HVA, crosses the blood-brain barrier to the CSF with relative ease (Kopin et al. 1983; Pletscher et al. 1967; Guldberg and Yates 1968). Therefore, the earlier estimate of the CNS contribution of MHPG to plasma and urine has been revised downward to about one-third and correlations between CSF and plasma are not taken as indicating that a significant amount of plasma MHPG is derived from the CNS. This fact, along with other problems noted next, tends to confound the interpretation of MHPG data that are obtained in patients who are receiving $\mathrm{DBQ}$. There seems to be little question that the administration of $D B Q$ results in a decrement of MHPG in plasma, CSF, and urine (Maas et al. 1988; Swann et al. 1980; Riddle et al. 1986), but 
the degree to which this decrease is of central origin remains open to question. In the report by Maas et al. (1979a) it was found that DBQ administration resulted in a decrement of MHPG production by brain. This was somewhat surprising since DBQ does not cross the blood-brain barrier and in these same experiments DBQ did not produce a change in the CNS production of HVA. Also in a previous paper (Maas et al. 1988), we found that DBQ administration was associated with a $2.8 \mathrm{ng} / \mathrm{ml}$ fall in plasma and a $5 \mathrm{ng} / \mathrm{ml}$ fall in CSF, i.e., the fall in CSF MHPG alone was too great to be accounted for solely by the fall in plasma MHPG. Therefore the more conservative interpretation would be that the reduction in MHPG in CSF, plasma, and urine is probably due to a peripheral inhibition of $\mathrm{MAO}$ as well as some indirect action of DBQ on the brain. For example, DBQ is an antihypertensive drug and it may be that by initiating changes in the peripheral NE system there are also compensatory changes in CNS NE activity. In unpublished experiments (G Aghajanian and JW Maas) we have found that acute treatment of rats with DBQ does not alter locus coeruleus (LC) unit recordings but we do not have data regarding the effects on furing rates of the $L C$ when DBQ is given chronically. We have also found, but not published (A Swann et al.), that administration of DBQ to rats produces a small fall in brain MHPG but that the brain's concentration of MHPG has returned to normal by 24 hours.

The present results, taken in conjunction with the preclinical and clinical research work, lead us to hypothesize that alterations in both DA and NE brain systems are associated with schizophrenia/psychosis. This could occur because the systems are linked, i.e., there is evidence that NE system function may regulate some parts of the DA systems (Grenhoff and Svensson 1989). Alternatively, these two systems may be involved in producing different facets of the schizophrenic illness, i.e., the DA system is involved with positive but not negative symptoms whereas NE systems are related to both positive and negative symptoms.

\section{ACKNOWLEDGMENTS}

This study was supported by Grant MH40935 and Clinical Research Center Grant MO1-RR01346 from the National Institutes of Health, Bethesda, Maryland; Veterans Administration Medical Research Funds; and the Hugo A. Auler Professorship of Psychiatry. Hoffman-LaRoche Ltd of Quebec, Canada supplied the DBQ tablets. We thank the following for their active participation and assistance in this research: the staff of Unit 1C of the Audie L. Murphy Memorial Veterans' Hospital; Donna Irish, the project research nurse; and Rochelle Javors, Betsy Cuvelier, and Ray Benavides for technical assistance with the metabolite assays.

\section{REFERENCES}

Anggard E, Lewander T, Sjoquist B (1974): Determination of homovanillic acid turnover in man. Life Sci 15:111-122

Antelman SM, Caggiula AR (1977): Norepinephrine-dopamine interactions and behavior: A new hypothesis of stress-related interactions between brain norepinephrine and dopamine is proposed. Science 195:646-653

Ashcroft GW, Crawford TBB, Eccleston D, Sharman DF, Mac. Dougall EJ, Stanton JB, Binns JK (1966): 5-Hydroxyindole compounds in the cerebrospinal fluid of patients with psychiatric or neurological diseases. Lancet 2:1049-1052

Bacopoulos ND, Heninger GR, Roth RH (1978): Effects of haloperidol and probenecid on plasma and CSF dopa. mine metabolites in the rhesus monkey (Macaca Mulatta). Life Sci 23:1805-1812

Bacopoulos NG, Hattox SE, Roth RH (1979): 3,4-Dihydroxyphenylacetic acid and homovanillic acid in rat plasma: Possible indicators of central dopaminergic ac. tivity. Eur J Pharmacol 56:225-236

Berger PA, Faull KF, Kilkowski J, Anderson PJ, Kraemer H, Davis KL, Barchas JD (1980): CSF monoamine metabolites in depression and schizophrenia. Am J Psychiatry 137:174-180

Bowers MB Jr (1973): 5-Hydroxyindoleacetic acid (5HIAA) and homovanillic acid (HVA) following probenecid in acute psychotic patients treated with phenothiazines. Psy. chopharmacologia 28:309-318

Bowers MB Jr (1978): CSF acid monoamine metabolites in psychotic syndromes: What might they signify? Biol Psychiatry 13:375-383

Bowers MB Jr (1980): Biochemical processes in schizophrenia: An update. In Keith SJ, Mosher LR (eds), Special Report; Schizophrenia, 1980. Bethesda, National Institute of Mental Health, pp 27-37

Bowers MB Jr, Heninger GR, Gerbode FA (1969): Cerebrospinal fluid, 5-hydroxyindoleacetic acid and homovanillic acid in psychiatric patients. Neuropharmacology 8:255262

Bowers MB Jr, Swigar ME, Jatlow PI, Goicoechea N (1984): Plasma catecholamine metabolites and early response to haloperidol. J Clin Psychiatry 45:248-251

Breier A, Wolkowitz OM, Roy A, Potter WZ, Pickar D (1990): Plasma norepinephrine in chronic schizophrenia. Am] Psychiatry 147:1467-1470

Buhler HU, Da Prada M, Haefely W, Picotti GB (1978): Plasma adrenaline, noradrenaline and dopamine in man and different animal species. J Physiol 276:311-320

Bunney BS, Grace AA (1978): Acute and chronic haloperidol treatment: Comparison of effects on nigral dopaminergic cell activity. Life Sci 23:1715-1728

Bunney WE Jr (1978): Drug therapy and psychobiological re. search advances in the psychoses in the past decade. Am J Psychiatry 135:8-13

Carlsson A, Lindquist M (1963): Effect of chlorpromazine or haloperidol on formation of 3-methoxytyramine and normetanephrine in mouse brain. Acta Pharmacol Toxicol 20:140-144 
Davidson M, Kahn RS, Knott P, Kaminsky R, Cooper M, DuMont K, Apter S, Davis KL (1991a): Effects of neuroleptic treatment on symptoms of schizophrenia and plasma homovanillic acid concentrations. Arch Gen Psychiatry 48:910-913

Davidson M, Kahn RS, Powchik P, Warne P, Losonczy MF, Kaminsky R, Apter S, Jaff S, Davis KL (1991b): Changes in plasma homovanillic acid concentrations in schizophrenic patients following neuroleptic discontinuation. Arch Gen Psychiatry 48:73-76

Davila R, Manero E, Zumarraga M, Andia I, Schweitzer JW, Friedhoff AJ (1988): Plasma homovanillic acid as a predictor of response to neuroleptics. Arch Gen Psychiatry 45:564-567

Davis KL, Davidson M, Mohs RC, Kendler KS, Davis BM, Johns CA, DeNigris Y, Horvath TB (1985): Plasma homovanillic acid concentration and the severity of schizophrenic illness. Science 227:1601-1602

Davis KL, Kahn RS, Ko G, Davidson M (1991): Dopamine in schizophrenia: A review and reconceptualization. Am J Psychiatry 148:1474-1486

Elchisak MA, Polinsky RJ, Elbert MH, Modlin LT, Kopin IJ (1979): Kinetics of homovanillic acid and determination of its production rate in the rhesus monkey. Life Sci 24:1493-1502

Elsworth JD, Redmond DE, Roth RH (1982): Plasma and cerebrospinal fluid 3-methoxy-4-hydroxyphenylethylene glycol (MHPG) as indices of brain norepinephrine metabolism in primates. Brain Res 235:115-124

Farde L, Wiesel F-A, Halldin C, Sedvall G (1988): Central D2dopamine receptor occupancy in schizophrenic patients treated with antipsychotic drugs. Arch Gen Psychiatry 45:71-76

Farley IJ, PriceKS, McCullough E, Deck JHN, Hordynsky W, Hornykiewicz O (1978): Norepinephrine in chronic paranoid schizophrenia: Above-normal levels in limbic forebrain. Science 200:456-457

Farley IJ, Shannak KS, Hornykiewicz O (1980): Brain monoamine changes in chronic paranoid schizophrenia and their possible relation to increased dopamine receptor sensitivity. Adv Biochem Psychopharmacol 21:427-433

Freedman R, Kirch D, Bell J, Adler LE, Pecevich M, Pachtman E, Denver P (1982): Clonidine treatment of schizophrenia: double-blind comparison to placebo and neuroleptic drugs. Acta Psychiatr Scand 65:35-45

Gershon S, Hekimian LJ, Floyd A Jr, Hollister LE (1967): a-Methyl-p-tyrosine (AMT) in schizophrenia. Psychopharmacologia 11:189-194

Glazer WM, Charney DS, Heninger GR (1987): Noradrenergic function in schizophrenia. Arch Gen Psychiatry 44:898-904

Comes UCR, Shanley BC, Potgieter L, Roux JT (1980): Noradrenergic overactivity in chronic schizophrenia: Evidence based on cerebrospinal fluid noradrenaline and cyclic nucleotide concentrations. Br J Psychiatry 137:346-351

Grenhoff J, Svensson TH (1989): Clonidine modulates dopamine cell fring in rat ventral tegmental area. Eur J Pharmacol 165:11-18

Guldberg HC, Yates CM (1968): Some studies of the effects of chlorpromazine, reserpine and dihydroxphenylalanine on the concentration of homovanillic acid, 3,4-dihydroxyphenylacetic acid and 5-hydroxyindol-3-ylacetic acid in ventricular cerebrospinal fluid of the dog using the technique of serial sampling of the cerebrospinal fluid. $\mathrm{Br} \mathrm{J}$ Pharmacol Chemother 33:457-471

Haracz JL (1982): The dopamine hypothesis: An overview of studies with schizophrenic patients. Schizophrenia Bull 8:438-469

Harris PQ, Brown SJ, Friedman MJ, Bacopoulos NG (1984): Plasma drug and homovanillic acid levels in psychotic patients receiving neuroleptics. Biol Psychiatry 19: 849-860

Helger R, Rindfrey H, Eilgenfeldt J (1974): Eine methode zur direkten bestimmung des creatinins in serum und harn ohne enteiwissung nach einer modifızierten JaffeMethode. Z Klin Chem Klin Biochem 12:344-349

Honigfeld G, Klett CJ (1965): The Nurses' Observation Scale for inpatient evaluation. J Clin Psychol 21:65-71

Hornykiewicz O (1978): Psychopharmacological implications of dopamine and dopamine antagonists: A critical evaluation of current evidence. Neuroscience 3:773-783

Javaid JI, Sharma RP, Janicak PG, Davis JM (1990): Plasma HVA in psychiatric patients: Longitudinal studies. Psychopharmacol Bull 26:361-365

Joseph MH, Baker HF, Johnstone EC, Crow TJ (1976): Determination of 3-methoxy-4-hydroxyphenylglycol conjugates in urine. Application to the study of central noradrenaline metabolism in unmedicated chronic schizophrenic patients. Psychopharmacology 51:47-51

Karoum F, Wyatt R, Costa E (1974): Estimation of the contribution of peripheral and central noradrenergic neurones to urinary 3-methoxy-4-hydroxyphenylglycol in the rat. Neuropharmacology 13:165-176

Kemali D, Del Vecchio M, Maj M(1982): Increased nonadrenaline levels in CSF and plasma of schizophrenic patients. Biol Psychiatry 17:711-717

Kendler KS, Mohs RC, Davis KL (1983): The effects of diet and physical activity on plasma homovanillic acid in normal human subjects. Psychiatry Res 8:215-224

Kitchin AH, Turner RWD (1966): Studies on debris oquin sulfate. Br Med J 2:728-731

Ko GN, Jimerson DC, Wyatt RJ, Bigelow LB (1988): Plasma 3-methoxy-4-hydroxyphenylglycol changes associated with clinical state and schizophrenic subtype. Arch Gen Psychiatry 45:842-846

Kopin IJ, Bankiewicz KS, Harvey-White J (1988): Assessment of brain dopamine metabolism from plasma HVA and MHPG during debrisoquin treatment: Validation in monkeys treated with MPTP. JNeuropsychopharm 1:119-125

Kopin IJ, Gordon EK, Jimerson DC, Polinsky RJ (1983): Relation between plasma and cerebrospinal fluid levels of 3-methoxy-4-hydroxyphenylglycol. Science 219:73-75

Lambert GW, Eisenhofer G, Cox HS, Horne M, Kalff V, Kelly M, Jennings GL, Esler MD (1991): Direct determination of homovanillic acid release from the human brain, an indicator of central dopaminergic activity. Life Sci 49: 1061-1072 
Maas JW, Hattox SE, Martin DM, Roth RH (1977): A direct method for studying brain amine metabolism in awake animals. In Usdin E, Weiner N, Youdim MBH (eds), Structure and Function of Monoamine Enzymes. New York, Marcel Dekker, pp 811-820

Maas JW, Hattox SE, Landis DH (1979a): Differential effects on brain catecholamines by debrisoquin. Biochem Pharmacol 28:3153-3156

Maas JW, Hattox SE, Martin DM, Landis DH (1979b): A directmethod for determining dopamine synthesis and output of dopamine metabolites from brain in awake animals. J Neurochem 32:839-843

Maas JW, Hattox SE, Greene NM, Landis DH (1980): Estimates of dopamine and serotonin synthesis by the awake human brain. J Neurochem 34:1547-1549

Maas JW, Contreras SA, Bowden CL, Weintraub SE (1985): Effects of debrisoquin on CSF and plasma HVA concentrations in man. Life Sci 36:2163-2170

Maas JW, Contreras SA, Seleshi E, Bowden CL (1988): Dopamine metabolism and disposition in schizophrenic patients: studies using debrisoquin sulfate. Arch Gen Psychiatry 45:553-559

Medina MA, Giachetti A, Shore PA (1969): On the physiological disposition and possible mechanism of the antihypertensive action of debrisoquin. Biochem Pharmacol 18:891-901

Meltzer HY, Stahl SM (1976): The dopamine hypothesis of schizophrenia: A review. Schizophrenia Bull 2:19-76

Miller AL, Keenan RW, Maas JW, Asch RH (1987): Disposition of homovanillic acid in the primate. Metab Brain Dis 2:207-212

Murphy DL, Wright C, Buchsbaum M, Nichols A, Costa JL, Wyatt RJ (1976): Platelet and plasma amine oxidase activity in 680 normals: sex and age differences and stability over time. Biochem Med 16:254-265

Muscettola G, Barbato G, de Bartolomeis A, Monteleone P, Pickar D (1990): Plasma HVA, tardive dyskinesia and psychotic symptoms in long-term drug-free inpatients with schizophrenia. Psychiatry Res 33:259-267

Nasrallah HA, Donnelly EF, Bigelow LB, Rivera-Calimlim L, Rogol A, Potkin S, Rauscher FP, Wyatt RJ, Gillin JC (1977): Inhibition of dopamine synthesis in chronic schizophrenia: Clinical ineffectiveness of metyrosine. Arch Gen Psychiatry 34:649-655

Nyback H, Berggren B-M, Hindmarsh T, Sedvall G, Wiesel F-A (1983): Cerebroventricular size and cerebrospinal fluid monoamine metabolites in schizophrenic patients and healthy volunteers. Psychiatry Res 9:301-308

Overall J, Gorham DR (1992): The Brief Psychiatric Rating Scale. Psycholog Rep 10:799-812

Persson T, Roos BE (1969): Acid metabolites from monoarnines in cerebrospinal fluid of chronic schizophrenics. Br J Psychiatry 115:95-98

Pickar D, Labarca R, Linnoila M, Roy A, Hommer D, Everett D, Paul SM (1984): Neuroleptic-induced decrease in plasma homovanillic acid and antipsychotic activity in schizophrenic patients. Science 225:954-957

Pickar D, Labarca R, Doran A, Wolkowitz OM, Roy A, Breier A, Lonnoila M, Paul SM (1986): Longitudinal measurement of plasma homovanillic acid levels in schizophrenic patients. Arch Gen Psychiatry 43:669-676
Pletscher A, Bartholini G, Tissot R (1967): Metabolic fate of $\left[{ }^{14} \mathrm{C}\right] \mathrm{DOPA}$ in cerebrospinal fluid and blood plasma of humans. Brain Res 4:106-109

Potter WZ, Hsiao JK, Goldman SM (1989): Effects of renal clearance on plasma concentrations of homovanillic acid. Arch Gen Psychiatry 46:558-562

Riddle MA, Leckman JF, Cohen DJ, Anderson M, Ort SI, Caruso KA, Shaywitz BA (1986): Assessment of central dopaminergic function using plasma-free homovanillic acid after debrisoquin administration. J Neural Transm 67:31-43

Rimon R, Roos B-E, Rakkolainen V, Alanen Y (1971): The content of 5-hydroxyindoleacetic acid and homovanillic acid in the cerebrospinal fluid of patients with acute schizo. phrenia. J Psychosom Res 15:375-378

Seeman P, Bzowej NH, Guan HC, Bergeron C, Reynolds GP, Bird ED, Riederer P, Jellinger K, Tourtellotte WW (1987): Human brain $D_{1}$ and $D_{2}$ dopamine receptors in schizo phrenia, Alzheimer's, Parkinson's and Huntington's dis eases. Neuropsychopharmacology 1:5-15

Snider SR, Kuchel O (1983): Dopamine: An important neurohormone of the sympathoadrenal system. Significance of increased peripheral dopamine release for the human stress response and hypertension. Endocrin $\operatorname{Rev} 4$ : 291-309

Spitzer RL, Endicott J (1979): Schedule for Affective Disorders and Schizophrenia. 3rd ed. New York, Biometrics Research Division, New York State Psychiatric Institute

Spitzer RL, Endicott J, Robins E (1978): Research Diagnostic Criteria: Rationale and reliability. Arch Gen Psychiatry 35:773-782

Stein L, Wise CD (1971): Possible etiology of schizophrenia: Progressive damage to the noradrenergic reward system by 6-hydroxydopamine. Science 171:1032-1036

Sternberg DE, van Kammen DP, Lake CR, Ballenger JC, Marder SR, Bunney WE Jr (1981): The effect of pimozide on CSF norepinephrine in schizophrenia. Am J Psychiatry 138:1045-1051

Sternberg DE, Charney DS, Heninger GR, Leckman JF, Hafstad KM, Landis DH (1982): Impaired presynaptic regulation of norepinephrine in schizophrenia. Effects of clonidine in schizophrenic patients and normal controls. Arch Gen Psychiatry 39:285-289

Swann AC, Maas JW, Hattox SE, Landis DH (1980): Catecholamine metabolites in human plasma as indices of brain function: Effects of debrisoquin. Life Sci 27:18571862

Thiemann S, Csernansky JG, Berger PA (1987): Rating scales in research: The case of negative symptoms. Psychiatry Res 20:47-55

Tomlinson DR, Mayor D (1973): The effects of guanethidine, bretylium and debrisoquine on the accumulation of noradrenaline in constricted postganglionic sympathetic nerves in vitro. Eur J Pharmacol 21:161-170

van Kammen DP (1977): GABA and the dopamine hypothesis of schizophrenia. Am J Psychiatry 134:138-143

van Kammen DP, Antelman S (1984): Impaired noradrenergic transmission in schizophrenia? Life Sci 34:1403-1413

van Kammen DP, Peters JL, van Kammen WB, Rosen J, Yao JK, McAdam D, Linnoila M (1989): Clonidine treatment 
of schizophrenia: Can we predict treatment response? Psychiatry, Res 27:297-311

rn Kammen DP, Peters J, Yao J, van Kammen WB, Neylan T, Shaw D, Linnoila M (1990): Norepinephrine in acute exacerbations of chronic schizophrenia. Arch Gen Psychiatry 47:161-168

Van Loon GR, Schwartz L, Sole MJ (1979a): Plasma dopamine responses to standing and exercise in man. Life Sci 24:2273-2278
Van Loon GR, Sole MJ, Bain J, Ruse JL (1979b): Effects of bromocriptine on plasma catecholamines in normal men. Neuroendocrinology 28:425-434

van Praag HM (1977): The significance of dopamine for the mode of action of neuroleptics and pathogenesis of schizophrenia. Br J Psychiatry 130:463-474

Winblad B, Bucht G, Gottfries CG, Roos BE (1979): Monoamines and monoamine metabolites in brains from demented schizophrenics. Acta Psychiatr Scand 60:17-28 